\title{
Acute anterior uveitis after discontinuation of tocilizumab in a patient with rheumatoid arthritis
}

This article was published in the following Dove Press journal:

Clinical Ophthalmology

8 January 2014

Number of times this article has been viewed

\section{Tomohito Sato' \\ Shinya Minakuchi' \\ Manabu Mochizuki² \\ Masaru Takeuchi' \\ 'Department of Ophthalmology, National Defense Medical College, Saitama, Japan; ${ }^{2}$ Department of Ophthalmology and Visual Science, Tokyo Medical and Dental University Graduate School of Medicine, Tokyo, Japan}

Background: Tocilizumab is a humanized monoclonal anti-interleukin-6 (IL-6) receptor antibody and has been approved in Japan for the treatment of Castleman's disease, rheumatoid arthritis (RA), and systemic juvenile idiopathic arthritis. Conjunctivitis and dry eye are known ocular adverse effects, but uveitis has not been reported.

Case report: A 72-year-old woman had undergone bilateral cataract surgery without complications. Six months after the surgery, she was diagnosed with RA and treated with tocilizumab infusion every 4 weeks. However, severe malaise and dizziness occurred after the third tocilizumab infusion, and the treatment was suspended. Since the symptoms associated with RA had resolved, she was followed without any medication thereafter. At 5 weeks after the third tocilizumab infusion, she developed severe anterior inflammation with hypopyon in her left eye, and her visual acuity dropped to less than $2 / 200$. Considering her age and history of cataract surgery, endophthalmitis was suspected and a vitrectomy was performed, but no pathogens were detected from the intraocular fluid samples collected during surgery. The ocular inflammation was gradually resolved with systemic antibiotics and corticosteroids. However, severe anterior uveitis recurred in the same eye during the tapering of the systemic corticosteroids, when the aqueous humor IL-6 level was 46,100 pg/mL. The recurrent ocular inflammation was resolved with increased doses of topical and systemic corticosteroids, and the patient has since remained relapse-free. No symptom of inflammation was observed in the right eye during the follow-up period.

Conclusion: This case indicates a possibility that acute anterior uveitis may have been an adverse effect after the discontinuation of anti-IL- 6 receptor antibody therapy in a patient with RA.

Keyword: interleukin-6

\section{Introduction}

Tocilizumab is a humanized anti-interleukin-6 (IL-6) receptor monoclonal antibody of the immunoglobulin (Ig)G1 subclass. ${ }^{1}$ Tocilizumab inhibits the binding of IL-6 to its receptors and decreases the proinflammatory activity of IL- 6 by competing with the soluble and membrane-bound IL-6 receptors. ${ }^{1}$ Tocilizumab has been approved in Japan for the treatment of Castleman's disease, rheumatoid arthritis (RA), and systemic juvenile idiopathic arthritis. ${ }^{1}$ Regarding the adverse effects of tocilizumab, serious infections and malignancies have been reported to occur in $18 \% .{ }^{2}$ Although conjunctivitis and dry eye are known ocular adverse effects, ${ }^{3}$ uveitis has not been reported. Here, we report a case of acute anterior uveitis after discontinuation of tocilizumab monotherapy for RA.

\section{Case report}

A 72-year-old woman presented with sudden loss of vision without pain in the left eye. Bilateral cataract surgery has been performed 6 months prior. At around 4 months before 
presentation, she was diagnosed with RA and had started tocilizumab monotherapy at a dose of $8 \mathrm{mg} / \mathrm{kg}$ every 4 weeks. However, the tocilizumab was discontinued after the third infusion, due to severe malaise and dizziness. Five weeks after the third infusion, she experienced a sudden decrease of vision. At presentation, the best corrected visual acuity (BCVA) was less than 2/200 in her left eye. An ophthalmological examination revealed severe anterior uveitis with hypopyon (Figure 1A) and anterior vitritis but no apparent retinal lesion. There were no symptoms related to Behçet's disease or human leukocyte antigen (HLA)-B27-associated acute anterior uveitis, and serologic tests for HLA typing were negative for HLA-A26, ${ }^{4}$ A29, ${ }^{5}$ B27, and B51. Because of the recent history of cataract surgery, the inflammatory symptoms led to a strong suspicion of delayed postoperative endophthalmitis. In addition to intravenous antibiotics, a diagnostic and therapeutic vitrectomy was performed. The obtained aqueous humor and vitreous samples were subjected to culture for bacteria and fungus, as well as multiplex polymerase chain reaction (PCR) for detection of human herpes viruses $1-8,{ }^{6}$ bacterial $16 \mathrm{~S}$ ribosomal ribonucleic acid (rRNA), ${ }^{7}$ and fungus $28 \mathrm{~S}$ rRNA. ${ }^{8}$ However, no pathogens were detected from any ocular samples by these tests. Intravenous infusions of betamethasone $4 \mathrm{mg} /$ day were initiated in addition to antibiotics, and the ocular inflammation improved gradually. After treatment with antibiotics and betamethasone was terminated on the eleventh postoperative day, cell infiltration into the anterior chamber increased on the next day, and the intravenous infusions of betamethasone $4 \mathrm{mg} /$ day was restarted. Subsequently, the uveitis was ameliorated, and the anti-inflammatory treatment with intravenous betamethasone $4 \mathrm{mg}$ /day was replaced by oral prednisolone $20 \mathrm{mg} /$ day, on the 18th postoperative day.

However, the uveitis recurred again in the left eye on the 43rd postoperative day despite the ongoing treatment with prednisolone $20 \mathrm{mg} /$ day, and the IL-6 level in the aqueous humor was $46,100 \mathrm{pg} / \mathrm{mL}$. The recurrent uveitis was improved by an

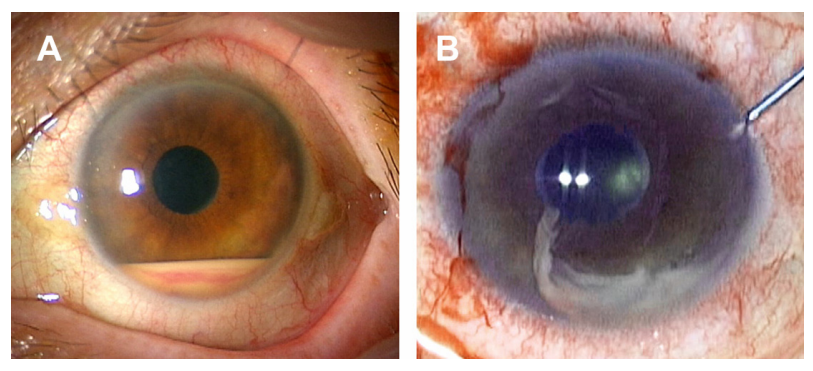

Figure I Anterior segment photographs at initial onset of anterior uveitis. Notes: (A) At initial onset, hypopyon with hemorrhage and minute granulomatous keratic precipitates, in the anterior chamber, are observed. (B) During anterior chamber lavage in vitrectomy, the hypopyon appears to have high viscosity. additional subconjunctival injection of $2 \mathrm{mg}$ of betamethasone. The patient has since remained relapse-free, with BCVA maintained at 20/20 (Figure 2). No symptom of inflammation was observed in the right eye during the follow-up period.

This case report did not require Institutional Review Board/Ethics Committee approval.

\section{Discussion}

IL-6 is a proinflammatory cytokine that stimulates various immune cells, ${ }^{9}$ such as T cells, B cells, monocytes, and macrophages, and is produced excessively in patients with RA. ${ }^{1}$ Tocilizumab is a humanized anti-IL-6 receptor antibody that reduces the proinflammatory activity of IL- $6 .{ }^{1}$ In the treatment of RA, disease-modifying antirheumatic drugs (DMARDs) and/or methotrexate have been used as the anchor drugs, ${ }^{10,11}$ while anti-tumor necrosis factor- $\alpha$ as well as anti-IL-6 receptor are newly approved agents. ${ }^{1}$ In the present case, instead of combination therapy with tocilizumab and methotrexate, tocilizumab monotherapy was selected because interstitial pneumonitis was suspected, from imaging studies using chest computed tomography. When the fourth tocilizumab infusion was postponed, the patient was observed without the use of DMARDs because the rheumatologist judged that the malaise and dizziness were transient.

Delayed postoperative endophthalmitis is characterized as an insidious inflammation occurring after intraocular surgery, ${ }^{12}$ several weeks or months after the surgery. Although the incidence of delayed postoperative endophthalmitis is unclear, ${ }^{12}$ the etiologies are considered to be latent infection by low-virulent bacteria, such as Propionibacterium acnes, ${ }^{12}$ and allergic reaction to the intraocular lens materials. ${ }^{12,13}$ In postoperative endophthalmitis, the inflammation is initially resolved by steroid administration but recurs after steroid tapering. ${ }^{12}$ In our present case, although the possibility of postoperative endophthalmitis cannot be denied, pathogens were not detected from the intraocular samples, even by multiplex PCR analysis.

The uveitis recurred on the 43rd postoperative day, while prednisolone $20 \mathrm{mg}$ /day was being given for tapering. Since $20 \mathrm{mg} /$ day of prednisolone should be an adequate dose, we gave one subconjunctival injection of $2 \mathrm{mg}$ of betamethasone instead of increasing the systemic steroid dose, resulting in the gradual resolution of the recurrent uveitis. In this case, relatively rapid tapering from intravenous betamethasone $4 \mathrm{mg}$ /day to oral prednisolone $20 \mathrm{mg}$ /day may have accounted for the recurrence.

Tocilizumab binds the IL-6 receptor and inhibits IL-6 signaling competitively, but tocilizumab does not prevent IL-6 
A

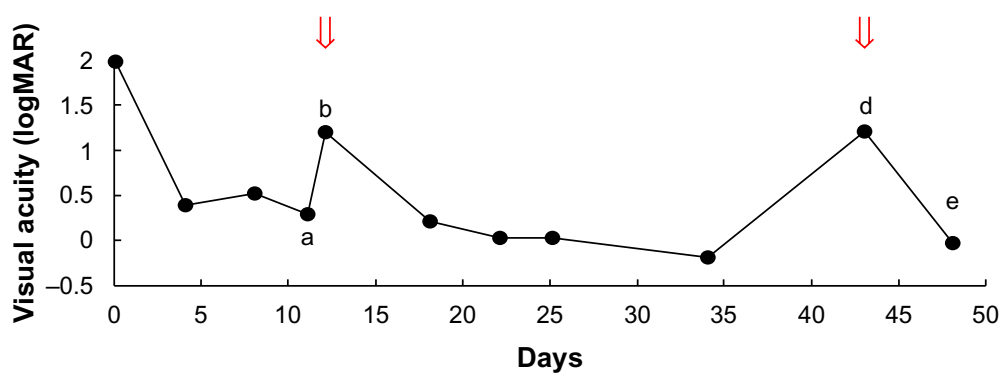

B

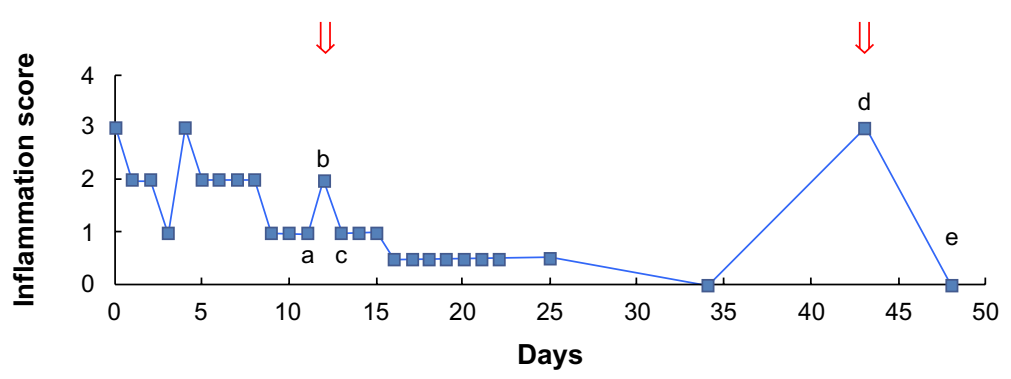

C

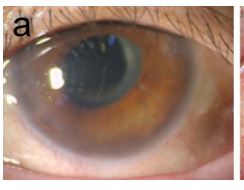

Day 11

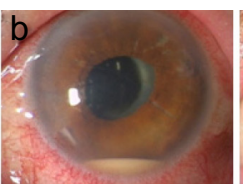

Day 12

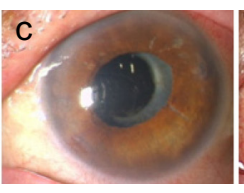

Day 17

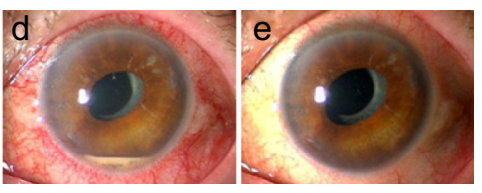

Day 43

Day 48

D

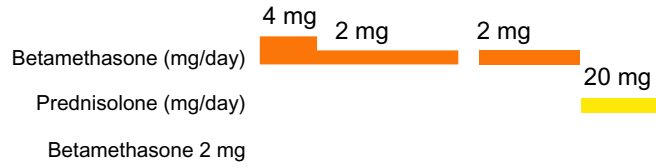

Figure 2 Clinical course of symptoms and treatments.

Notes: (A) Time course of visual acuity. The arrows denote the recurrence of uveitis. (B) Time course of the anterior inflammation score. The arrows denote the recurrence of uveitis. (C) Time-lapse photographs of the anterior segment. (D) Course of systemic and/or topical steroid administration. The arrow denotes the subconjunctival injection of $2 \mathrm{mg}$ of betamethasone. Lowercase letters a-e shown in A-C correlate with each other.

production by IL-6 secretory cells. ${ }^{14}$ The serum concentration of IL-6 is elevated in patients with RA and correlates with RA activity. ${ }^{15}$ One report demonstrated that the serum concentrations of IL- 6 and soluble IL-6 receptor increased after tocilizumab administration in patients with RA and that the concentrations remained high, even on the 42nd day after administration. ${ }^{14}$ IL- 6 concentrations in intraocular fluids are elevated with the development of inflammatory uveitis. ${ }^{16-19}$ It is likely that the levels were also elevated in our case, although we did not measure them at initial onset of uveitis. However at the time of the recurrence, the aqueous humor IL-6 concentration was $46,000 \mathrm{pg} / \mathrm{mL}$, which is extremely high even compared with those reported in uveitic eyes. ${ }^{16-19}$ In this case, we postulate that IL-6 may have been produced excessively during the tocilizumab therapy, whereas inhibition of IL-6 signaling was diminished after the discontinuation of the tocilizumab, and that the excessive IL-6 persisting for a transient period may have caused anterior inflammation, clinically recognized as acute anterior uveitis.

\section{Acknowledgments}

We thank Dr Sunao Sugita and Dr Manabu Ogawa for their technical support.

\section{Disclosure}

The authors report no conflicts of interest in this work.

\section{References}

1. Venkiteshwaran A. Tocilizumab. MAbs. 2009;1(5):432-438.

2. Nishimoto N, Hashimoto J, Miyasaka N, et al. Study of active controlled monotherapy used for rheumatoid arthritis, an IL-6 inhibitor (SAMURAI): evidence of clinical and radiographic benefit from an $\mathrm{x}$ ray reader-blinded randomised controlled trial of tocilizumab. Ann Rheum Dis. 2007;66(9):1162-1167. 
3. Info.pmda.go.jp [homepage on the Internet]. [Actemra ${ }^{\circledR}$ interview form]. Pharmaceuticals and Medical Devices Agency; 2013 [cited September 22, 2013]. Available from: http://chugai-pharm.jp/hc/di/scholar/item/ drug_data/act/if/act_if.pdf. Accessed Nov 2013. Japanese.

4. Kurata R, Nakaoka H, Tajima A, et al. TRIM39 and RNF39 are associated with Behçet's disease independently of HLA-B*51 and -A*26. Biochem Biophys Res Commun. 2010;401(4):533-537.

5. Bergink GJ, Ooyman FM, Maas S, Rademakers AJ. Three HLA-A29 positive patients with uveitis. Acta Ophthalmol Scand. 1996;74(1): 81-83.

6. Sugita S, Shimizu N, Watanabe K, et al. Use of multiplex PCR and real-time PCR to detect human herpes virus genome in ocular fluids of patients with uveitis. Br J Ophthalmol. 2008;92(7):928-932.

7. Sugita S, Shimizu N, Watanabe K, et al. Diagnosis of bacterial endophthalmitis by broad-range quantitative PCR. Br J Ophthalmol. 2011;95(3):345-349.

8. Ogawa M, Sugita S, Watanabe K, Shimizu N, Mochizuki M. Novel diagnosis of fungal endophthalmitis by broad-range real-time PCR detection of fungal 28S ribosomal DNA. Graefes Arch Clin Exp Ophthalmol. 2012;250(12):1877-1883.

9. Melton L, Coombs A. Actemra poised to launch IL-6 inhibitors. Nat Biotechnol. 2008;26(9):957-959.

10. Funovits J, Aletaha D, Bykerk V, et al. The 2010 American College of Rheumatology/European League Against Rheumatism classification criteria for rheumatoid arthritis: methodological report phase I. Ann Rheum Dis. 2010;69(9):1589-1595.

11. Aletaha D, Neogi T, Silman AJ, et al. 2010 Rheumatoid arthritis classification criteria: an American College of Rheumatology/European League Against Rheumatism collaborative initiative. Arthritis Rheum. 2010;62(9):2569-2581.
12. Lemley CA, Han DP. Endophthalmitis: a review of current evaluation and management. Retina. 2007;27(6):662-680.

13. Mamalis N, Edelhauser HF, Dawson DG, Chew J, LeBoyer RM, Werner L. Toxic anterior segment syndrome. J Cataract Refract Surg. 2006;32(2):324-333.

14. Nishimoto N, Terao K, Mima T, Nakahara H, Takagi N, Kakehi T. Mechanisms and pathologic significances in increase in serum interleukin-6 (IL-6) and soluble IL-6 receptor after administration of an anti-IL-6 receptor antibody, tocilizumab, in patients with rheumatoid arthritis and Castleman disease. Blood. 2008;112(10):3959-3964.

15. Usón J, Balsa A, Pascual-Salcedo D, et al. Soluble interleukin 6 (IL-6) receptor and IL-6 levels in serum and synovial fluid of patients with different arthropathies. J Rheumatol. 1997;24(11):2069-2075.

16. Murray PI, Hoekzema R, van Haren MA, de Hon FD, Kijlstra A. Aqueous humor interleukin-6 levels in uveitis. Invest Ophthalmol Vis Sci. 1990;31(5):917-920.

17. de Boer JH, van Haren MA, de Vries-Knoppert WA, et al. Analysis of IL-6 levels in human vitreous fluid obtained from uveitis patients, patients with proliferative intraocular disorders and eye bank eyes. Curr Eye Res. 1992;11 Suppl:S181-S186.

18. Ongkosuwito JV, Feron EJ, van Doornik CE, et al. Analysis of immunoregulatory cytokines in ocular fluid samples from patients with uveitis. Invest Ophthalmol Vis Sci. 1998;39(13):2659-2665.

19. Curnow SJ, Falciani F, Durrani OM, et al. Multiplex bead immunoassay analysis of aqueous humor reveals distinct cytokine profiles in uveitis. Invest Ophthalmol Vis Sci. 2005;46(11):4251-4259.
Clinical Ophthalmology

\section{Publish your work in this journal}

Clinical Ophthalmology is an international, peer-reviewed journal covering all subspecialties within ophthalmology. Key topics include: Optometry; Visual science; Pharmacology and drug therapy in eye diseases; Basic Sciences; Primary and Secondary eye care; Patient Safety and Quality of Care Improvements. This journal is indexed on Submit your manuscript here: http://www.dovepress.com/clinical-ophthalmology-journal

\section{Dovepress}

PubMed Central and CAS, and is the official journal of The Society of Clinical Ophthalmology (SCO). The manuscript management system is completely online and includes a very quick and fair peer-review system, which is all easy to use. Visit http://www.dovepress.com/ testimonials.php to read real quotes from published authors. 